\title{
Owen Heathcote, From Bad Boys to New Men? Masculinity, Sexuality and Violence in the Work of Éric Jourdan
}

Oxford, Peter Lang, coll. « Modern French Identities », 2014, 250 p.

\section{Chantal Chawaf}

Il existe une critique qui substitue à la critique traditionnellement intellectuelle, rationnelle et distanciée, une démarche littéraire affective proche, presque intime, d'où la puissance de pénétration de cette critique originale. Cette façon de communiquer, d'enseigner, d'analyser un texte ou une œuvre sans se tenir à distance ne procède pas par parabole comme les apôtres du Nouveau Testament, mais se base elle 
aussi sur la foi, la foi dans la littérature, et s'appuie sur son identification à l'œuvre commentée en offrant au livre élu le credo, l'intériorité d'un engagement qui ne cherche pas à convertir (car cette forme nouvelle de critique s'enracine dans une stricte rigueur) mais qui cherche, en témoignant par les sens et par l'émotion, à partager ses sentiments avec nous, à les diffuser en nous, ce qui a ainsi pour conséquence d'éveiller chez nous notre propre réflexion, notre propre dialectique, autrement dit, notre vif intérêt pour l'œuvre abordée par cette critique généreuse, non intrusive mais si entière qu'elle nous fait entrer en profondeur dans la création d'un écrivain qu'elle nous convainc alors de nous précipiter de lire, avec la liberté d'être réceptif ou non, au message simultané du critique et du romancier. Ce nouveau critique, et il s'agit ici d'Owen Heathcote, excelle à être un initiateur en décloisonnement des genres en littérature, à nous introduire dans l'œuvre qui, lue ensuite par nous, passera ou ne passera pas nos propres cloisonnements mais remettra immanquablement en question nos propres structures, les ébranlera, les supprimera ou au contraire les renforcera, et peut-être tout ensemble : le critique littéraire n'est-il pas, avant tout, un médium, une poussée de littérature qui agit sur la conscience, en explore la complexité?

Les sociétés sont verrouillées, le langage est étiqueté, il y a les mots sur les étiquettes: «homosexuel», «gay», " hétérosexuel», «féminin », « masculin »... La force, le talent, l'audace et la sincérité de l'écrivain Éric Jourdan, c'est d'ignorer le sens de ces mots conformistes et d'écrire en toute liberté les désirs et les plaisirs de son corps d'homme apte à jouir et à faire jouir, dans les bras des hommes ou dans ceux des femmes. Or l'efficacité remarquable de l'essai d'Owen Heathcote, c'est de démontrer comment ces mots de l'étiquetage - 
« homosexualité », « hétérosexualité » — doivent être effacés et remplacés par des mots plus justes, plus vrais : " homoérotisme », " pansexualisme » et tout simplement le mot « corps» - le corps en état de désir ou de plaisir, en action dans la ou les rencontre(s) amoureuse(s). La féminité de l'homme se libère dans la pensée neuve de cette critique qui nous rappelle que la féminité est un élément essentiel de la masculinité. La finesse de la mise au point entreprise dans le Bad Boys d'Owen Heathcote opère un salvateur travail d'unification dans la dualité conflictuelle et met en valeur la réconciliation que les personnages d'Éric Jourdan incarnent avec la crudité et même la sauvagerie d'un naturel qui tient aussi de l'allégorie dans les récits de ces unions obsessionnellement passionnelles, d'homme à homme, qui n'excluent ni la violence, ni la destruction, ni la haine, ni le meurtre, ni l'inceste, ni même la misogynie, puisqu'on n'expurge pas, puisqu'on ne censure plus... Owen Heathcote parle de l'avènement d'un homme nouveau, nouveau parce que libéré. Par contre, j'ajouterai personnellement que l'homme en gestation ne pourra pas naître tant qu'il ne donnera pas une place suffisante à la femme elle-même libérée et qu'il ne décloisonnera pas le psychosocial, à travers elle, en lui restituant sa féminité de femme, sa masculinité de femme, répondant à une problématique du réel des femmes qui restent marginalisées chez Éric Jourdan. Owen Heathcote perçoit cependant dans l'œuvre de Jourdan l'aube d'une éthique nouvelle qui se détache de l'éthique traditionnelle en la subvertissant, par la perturbation radicale provoquée par les héros de ces romans qui agressent hardiment l'ordre établi. Oui, sans doute, l'aube. L'aube prophétique des hommes nouveaux, mais une aube encore très imprégnée de nuit noire par ces 
«bad boys » qu'évoque Owen Heathcote à propos des hommes créés par Éric Jourdan. Précisément, il manque encore sans doute à ces hommes en renaissance la nette clarté de l'aube. Il leur manque encore d'approfondir l'autre phase de l'aube, non plus celle de la fin de l'obscurité, mais celle du début du jour et d'y intégrer l'autre moitié du monde, les femmes, qui, pas plus que les hommes, ne sont seulement sexualité, désirs, plaisirs et pulsions. La littérature d'Éric Jourdan a tendance à se concentrer sur une étape encore adolescente du renouveau, sur cette revendication vitale des corps amoureux et leur indispensable révolte contre l'autoritarisme de la société répressive. C'est là que le travail du langage sur le corps doit se poursuivre, se compléter et persévérer à se rapprocher toujours plus attentivement, plus courageusement de la réalité de la vie, au sens éthique et écologique d'une morale de la préservation de notre humanité, dans la dimension planétaire et non plus seulement individuelle et jouissive. Le livre d'Owen Heathcote, en éclairant les livres d'Éric Jourdan, nous met sur la piste... 